Gloria Martin-Saco

Alexander Tristancho

Antonina Arias

Isabel Ferrer

Ana Milagro

Juan M. García-Lechuz

\section{Mycoplasma genitalium and sexually transmitted infections: evidences and figures in a tertiary hospital}

Clinical Microbiology Department. Hospital Universitario Miguel Servet. Zaragoza. Spain.

Article history

Received: 21 June 2021; Revision Requested: 19 July 2021; Revision Received: 19 October 2021; Accepted: 29 October 2021;

Published: 17 December 2021

\section{ABSTRACT}

Introduction. Mycoplasma genitalium is an emerging cause of sexually transmitted infections (STIs) and has been implicated in non-gonococcal urethritis in men and cervicitis in woman. The aim of this study is determinate the incidence and pathogenicity of $M$. genitalium within the diagnosis of STIs detected from clinical samples in a third level hospital.

Material and methods. A total of 8,473 samples from endocervix, urethra, vagina, rectum and others were processed applying Allpex STI Essential Assay. More than 190 records were reviewed to determinate $M$. genitalium pathogenicity.

Results. M. genitalium was detected in a rate $2.8 \%$. Co-infections were detected in $20 \%$ of the patients.

Conclusions. M. genitalium is considered a STI emerging pathogen thanks to the renewal of multiplex-PCR tests although with a low incidence in our approach. Emerging from our experience and the institutional recommendations both detection of acid nucleic techniques (NAATs) and gonococcal culture might be implemented accurately and coexist to adequate prescriptions.

Keywords: Mycoplasma genitalium, sexually transmitted infections, coinfection
Mycoplasma genitalium en el renovado diagnóstico de las infecciones de transmisión sexual: evidencias y cifras en un hospital terciario

\section{RESUMEN}

Introducción. Mycoplasma genitalium es un patógeno emergente causante de infecciones de transmisión sexual (ITS) y se ha relacionado con uretritis no gonocócica en hombres y cervicitis en mujeres. El objetivo de este estudio es determinar la incidencia y patogenicidad de $M$. genitalium en el seno del diagnóstico de ITS detectadas a partir de muestras clínicas en un hospital terciario.

Métodos. Se procesaron 8.473 muestras de endocérvix, uretra, vagina, recto y otros, aplicando Allpex STI Essential Assay. Se revisaron más de 190 historias clínicas para determinar la patogenicidad de M. genitalium.

Resultados. Se detectó M. genitalium en 2,8\% de casos. Hubo coinfecciones en 20\% de los pacientes.

Conclusiones. M. genitalium a pesar de la baja incidencia en nuestra revisión, actualmente es un patógeno de valor en alza gracias al desarrollo de técnicas moleculares como PCRmultiplex. A partir de nuestra experiencia y las recomendaciones institucionales, tanto las técnicas de detección de ácidos nucleicos (NAATs) como los cultivos para gonococo deberían implementarse y coexistir para adecuar los tratamientos.

Palabras clave: Mycoplasma genitalium, infección de transmisión sexual, coinfección

\section{INTRODUCTION}

Mycoplasma genitalium is the smallest known self-replicating bacterium that cause non-gonococcal urethritis in men and cervicitis in women. Co-infections with M. genitalium and other bacterial sexually transmitted infections (STIS) have fre- 
quently reported. Its prevalence varies among sexually transmitted infection clinic attendees and the general population [1]. In our community, there is not a reference centre for attending STI patients and they are referred from Primary Care to specialities (dermatology, ginecology, infectious diseases) and directly to our microbiology lab at Miguel Servet Hospital (HUMS). The general purpose of this study was to determine the incidence and pathogenicity of $M$. genitalium within the STIs detected from clinical samples sent to our laboratory and discuss the renewal procedures and laboratory changes in the diagnosis of STI.

\section{MATERIAL AND METHODS}

A real-time PCR (Allplex STI Essential Assay by Seegene) was the detection method applied in vaginal, endocervical, and urethral samples. This assay detects simultaneously 7 microorganisms: Chlamydia trachomatis, Mycoplasma genitalium, Mycoplasma hominis, Neisseria gonorrhoeae, Trichomonas vaginalis, Ureaplasma parvum, Ureaplasma urealyticum. At the same time, samples were cultured on Columbia blood, Chocolate, VCA Neisseria gonorrhoeae and Sabouraud agar.

Antibiograms from positive cultures for Neisseria gonorrhoeae were done on GCll agar supplemented with Isovitalex (Becton-Dickinson) following the recommendations from EUCAST and using a control strain ATCC 49226.

From January 2019 to October 2020, 8,473 samples were processed from 6,058 patients. In this period, our hospital assisted a population of 586,835 inhabitants.

We reviewed the number of $M$. genitalium detected by PCR in this period and age, sex, co-infections and clinical evidence were analysed from the LIS records.

\section{RESULTS}

From 8,473 samples submitted to Allplex assay, M. genitalium was detected in $234(2.8 \%)$ from 232 patients (106 males; 126 females). The mean age was 29.8 years, being the group between 19 and 35 years old almost 70\% of the cases. Samples were from endocervix (103), urethra (84), vagina (18), urine (16), rectum (11), others (2).
From the review of 194 available clinical records about M. genitalium isolates, 43 (22\%) were clinically significant and were treated (52\% azithromycin, 32\% moxifloxacin, 16\% doxycycline). The median cycle threshold- (CT) was 25.3 in the infected group and 30.3 in the non-infected group. Therefore, during this period, the prevalence of $M$. genitalium was $0.07 \% 0$ and the incidence density rate was 3.8 new cases $/ 100$ patients/year.

The incidence rate of $N$. gonorrhoeae, $C$. trachomatis and $T$. vaginalis in the same period is presented in table 1. Despite the decrease in the number of samples in 2020 compared to the previous years, there was an 11\% of increase in the number of positive gonococcal cultures.

Co-infections were in 16/106 male patients with M. genitalium detected $(9 \mathrm{~N}$. gonorrhoeae, $6 \mathrm{C}$. trachomatis, $1 \mathrm{~T}$. vaginalis) and in 31/126 female patients (23 C. trachomatis, 5 T. vaginalis, 3 N. gonorrhoeae). M. genitalium was detected together with M. hominis (5) and U. urealyticum (4) with an uncertain value not clinically related.

\section{DISCUSSION}

M. genitalium is a considered pathogen but in our experience, the incidence was low and less than 25\% of patients with a positive sample was clinically significant and treated. Different consideration deserves the diagnosis of gonorrhoea established by the detection of $N$. gonorrhoeae at an infected site, either by nucleic acid amplification (NAATs) or by culture. Symptoms and signs of sexually acquired infection depend, in part, on the site of infection. One of the most important and scary pathogen, N. gonorrhoeae, is on an emerging trend since the last decade [2]. Co-existing infections such as $C$. trachomatis, T. vaginalis, M. genitalium, Candida albicans and conditions as bacterial vaginosis, are common and these should be considered for an optimal and efficacious treatment but its interpretation is often difficult [3].

The approach to diagnose any infectious diseases will be oriented by the clinical examination, but sexually transmitted diseases (STDs) need a more specific and in-depth oriented exam and interview of sexual behaviours [4].

Having fast NAAT tests allows a personalized, practical, preventive and predictive assistance. NAATs are more sensitive than culture, particularly for oropharyngeal and rectal

\begin{tabular}{l|cccc}
\hline Table 1 & \multicolumn{4}{|l}{$\begin{array}{l}\text { Prevalence and incidence rate of M. genitalium, } \\
\text { N. gonorrhoea, C. trachomatis and T. vaginalis } \\
\text { infections during the study period (2019-2020). }\end{array}$} \\
\hline & N. Cases & Population at risk & Prevalence \%o & Incidence rate \% \\
\hline M. genitalium & 43 & 6,058 & 0.07 & 0.7 \\
\hline N. gonorrhoea & 498 & 6,985 & 0.84 & 7.1 \\
C. trachomatis & 740 & 6,985 & 1.26 & 10.6 \\
\hline T. vaginalis & 186 & 6,985 & 0.32 & 2.7 \\
\hline
\end{tabular}


sites and they show high sensitivity (>95\%) in both symptomatic and asymptomatic infection but indirectly these tests promotes the detriment and oblivion of classical tests (rapid wet mount smear or Gram stain, special media cultures ...). So that, it is assumed that the primary role of culture is not for diagnostic purposes but for antimicrobial susceptibility testing prior to prescribe any treatment.

In the study of Salmeron et al. [5], a prospective multicentre study in ten hospitals in Spain (including ours), only 49\% of gonococcal infections had a positive culture available for antimicrobial susceptibility testing. Azithromycin resistance was found in 12\% and high-level resistance (MIC>256 mg/L) was detected in $0.1 \%$ of all cases. As long as antimicrobial resistance in $N$. gonorrhoeae continues spreading, cultures will survive. Despite the decrease in the number of samples and patients in 2020, we detected an 11\% of increase in the number of positive gonococcal cultures [6]. The rate of gonococcal resistance to azithromycin detected in our lab was between 19 and 24\% of the isolates and 64\% to ciprofloxacin. There was no isolate resistant to ceftriaxone. These are the reasons for the culture survival.

The detection of antimicrobial resistance genes enclosed in the multiplex PCR tests or the whole genome sequencing armamentarium threaten cultures to be banished. Nevertheless, the "multiplex" results of the NAATs must be interpreted cautiously, because bacteria as M. genitalium, M. hominis, U. urealyticum and $U$. parvum can pose confounding approaches, potential partner conflict and misuse of antibiotics. M. genitalium was detected in our study in a low rate $2.8 \%$ and a very low prevalence. From the review of near two hundred available clinical records, it was relevant in less than $25 \%$ of patients and treated.

Co-infections pose another growing barrier for specific implementation of prevention strategies. In our study, coinfections were detected in 47 patients (20\%), mainly M. genitalium and $C$. trachomatis (29 cases), or N. gonorrhoeae (12 cases) or T. vaginalis (5 cases). In the article of Rob et al [7], the prevalence of co-infections in men who have sex with men (MSM) was significantly higher (20\%) than in heterosexual men and women (4.2\%), and it was significantly associated with HIV infection. Syphilis, HIV together with N. gonorrhoeae and C. trachomatis show how co-infections can be missed in rectal and pharyngeal localizations in asymptomatic patients, who can further spread these co-infections [7].

In agreement with the comments from Roland C. Merchant in Annals of Emergency Medicine [8], accurate pointof-care rapid tests would permit the more efficient use of antimicrobials and would reduce the inherent difficulties in attempting to notify patients of their test results after their emergency department visit.

Emerging from our experience and the institutional recommendations $[9,10]$, both NAATs and primary and following cultures need to live together in good harmony and fitness to prevent the blind prescriptions from spreading fatal errors.

In a recent article published by Dumke et al. [11], about some important strategies to establish regional networks of laboratories that can perform gonococcal culture and resistant gene detection of M. genitalium (quinolones and macrolides), they highlight the importance of a good quality control mechanisms to detect treatment failures by developing a standard protocol of follow-up.

Our study has the limitation of the small number of patients with enough clinical data an also the default of a long follow-up of asymptomatic patients (just 3 months in symptomatic) and their partners to know the real prevalence and clinical impact of M. genitalium. Nevertheless, we did not take into account the positive samples of asymptomatic patients in accordance with recent publications and guidelines [12-14]. Screening of asymptomatic $M$. genitalium infection among women and men or extragenital testing for M. genitalium is not recommended.

In conclusion, M. genitalium is considered a STI pathogen thanks to the renewal of multiplex-PCR tests although with a low incidence in our approach.

\section{FUNDING}

None to declare

\section{CONFLICTS OF INTEREST}

The authors declare no conflict of interest

\section{REFERENCES}

1. Taylor-Robinson D, Jensen JS. Mycoplasma genitalium: from Chrysalis to multicolored butterfly. Clin Microbiol Rev 2011; 24 (3):498-514. doi: 10.1128/CMR.00006-11.

2. Stary A. The Changing Spectrum of Sexually Transmitted Infections in Europe. Acta Derm Venereol 2020; 100: 242-247. doi: 10.2340/00015555-3470

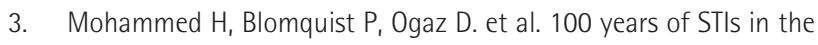
UK: a review of national surveillance data. Sex Transm Infect 2018; 94(8):553-558. doi: 10.1136/sextrans-2017-053273.

4. Workowski KA, Berman S. Sexually transmitted diseases treatment guidelines, 2010. MMWR Recomm Rep. 2010; 59(RR-12):1-110.

5. Salmerón P, Viñado B, Arando M et al. Neisseria gonorrhoeae antimicrobial resistance in Spain: a prospective multicentre study. J Antimicrob Chemother 2021;doi:10.1093/jac/dkab037.

6. Martin G, Tristancho A, Milagro A et al. Mycoplasma genitalium: evidences and figures in a tertiary hospital in Spain. Abstract 00845 ECCMID Viena 2021.

7. Rob F, Jůzlová K, Kružicová Z et al. Prevalence of Chlamydia trachomatis and Neisseria gonorrhoeae co-infections among patients with newly diagnosed syphilis: a single-centre, cross-sectional study. Cent Eur J Public Health 2019; 27(4):285-291

8. Merchant RC. Infectious disease. Update on emerging infections: news from the Centers for Disease Control and Prevention. Ann Emerg Med 2011; 58(1):67-8. 
9. MMWR Recomm Rep. Recommendations for the laboratory-based detection of Chlamydia trachomatis and Neisseria gonorrhoeae-2014; 63(RR-02):1-19.

10. WHO. Multi-drug resistant gonorrhoeae. Newsletter. 6th Nov 2020. www.who.int/news-room/fact-sheets/detail/multi-drug-resistant-gonorrhoeae

11. Dumke R, Ziegler T, Abbasi-Boroudjeni N, Rust M, Glaunsinger T. Prevalence of macrolide- and fluoroquinolone-resistant Mycoplasma genitalium strains in clinical specimens from men who have sex with men of two sexually transmitted infection practices in Berlin, Germany. J Glob Antimicrob Resist 2019; 18:118-121. doi: 10.1016 /j.jgar.2019.06.015.

12. Kirby T. Mycoplasma genitalium: a potential new superbug. Lancet Infect Dis 2018; 18: 951-952. doi: 10.1016/S1473-3099(18)30506-

1

13. Gnanadurai R, Fifer H. Mycoplasma genitalium: A Review. Microbiology 2020; 166: 21-29. doi: 10.1099/mic.0.000830.

14. Workowski KA, Bachmann LH, Chan PA et al. Sexually Transmitted Infections Treatment Guidelines, 2021. US Department of Health and Human Services/Centers for Disease Control and Prevention. MMWR Recomm Rep. 2021;70(4):1-187. doi: 10.15585/mmwr. rr7004a1. 